\title{
PROSTHODONTIC COMPLICATIONS ASSOCIATED WITH DENTAL IMPLANTS: A REVIEW OF LITERATURE
}

\author{
D.R. Prithviraj ${ }^{1 *}$, Rachana Srivastava ${ }^{1}$, Satyam Gaur ${ }^{1}$, Abhishekha Patil ${ }^{1}$, Sounder Raj $K^{1}$, \\ Shruthi D.P ${ }^{2}$ \\ ${ }^{1 *}$ Dept. of Prosthodontics, Govt. Dental College and Research Institute, Bangalore, Victoria Hospital Campus, \\ Fort, Bangalore- 560002 \\ ${ }^{2}$ Dept. of Orthodontics, Dayanand Sagar College of Dental Sciences, Bangalore
}

\begin{abstract}
Implant dentistry has evolved as the standard of care in past few decades. It has been benefiting the patients with predictable outcomes. Although higher success rates have been reported in the implant dentistry, there are several complications that do occur. Most of the complications can be minimized if the proper diagnosis and treatment plan is executed. The dentist should have a thorough knowledge regarding all the complications associated with dental implants, prevention strategies, and their management. Follow up after every 6 months has been advocated for the dental implant restorations. The patient should be informed about the anticipated complications and the probable outcome of the treatment. The purpose of this article is to describe the prosthodontic complications associated with dental implants and to discuss their prevention and management.Success of the dental implant has its own limitations.
\end{abstract}

Key-words: dental implants, mechanical complications, peri-implantitis, implant failure.

\section{INTRODUCTION}

Dental implants have proven to be the most promising and fastest growing technology since past 30 years. ${ }^{1}$ The first concern of the dentist during the dental implant treatment has always been to achieve sufficient amount of osseointegration. In the past, dental implants were considered successful, if the implant mobility is $<1 \mathrm{~mm}$ with least amount of radiolucency and bone loss. According to the International Congress of Oral Implantologists (Italy 2007), the dental implant with bone loss of $\leq 2 \mathrm{~mm}$ after the initial surgery with no signs of pain and mobility could be regarded as a successful implant.

Currently, the prime criteria for the implant success include the absence of implant mobility, radiolucency, and bone loss. According to various systematic reviews, the success rate of the dental implants is approximately $85-90 \%$. Success of the dental implant is not only determined by the osseointegration, but different periodontal factors along with the patient's perception also play an important role. ${ }^{2,3}$

Nowadays, dental implant procedure has become more popular among the dentists and the patients. Despite high success rates, several risk factors and complications have been reported in

*Corresponding author:

Email: prithvidr@yahoo.com

http://dx.doi.org/10.20530/IJTA $31 \quad 47-53$

ISSN 2320-138X @ 2016 various clinical reports. ${ }^{4}$ These complications may be surgical, mechanical, biological and esthetic/ phonetic. ${ }^{5}$ Reviewing patient's medical and dental records to prepare a security checklist was proposed by Christman et al, so that the dental implant complications can be anticipated before treatment planning and execution and, therefore, minimized. ${ }^{6}$

\section{SEARCH STRATEGY}

MEDLINE/ PubMed searches were conducted using the terms dental implants, implant complications, mechanical complications, periimplantitis, implant failure as well as combinations of these and related terms. The few articles judged to be relevant were reviewed.

\section{DENTAL IMPLANT COMPLICATIONS:}

Dental implant complications may be surgical or prosthodontic in nature.

\section{SURGICAL COMPLICATIONS}

Dental implant surgery may cause several surgical complications which include excessive bleeding due to damage to any major/minor blood vessel, prolonged paresthesia/anaesthesia that may be permanent if the underlying nerve is damaged. Other surgical complications include implant hitting to the adjacent tooth which may lead to devitalization of involved tooth, graft rejection/graft loss, implant or the graft material into the maxillary sinus. Post operative maxillary sinusitis, schneiderian membrane perforation and bisphosphonate-related osteoradionecrosis are 
the other surgical complications associated with dental implants.

Prosthodontic complications associated with dental implants can be broadly classified as biological, mechanical and aesthetic. ${ }^{1}$ (Table 1)

Table 1. Prosthodontic Complications associated with dental implants ${ }^{1}$

\begin{tabular}{ll}
\hline $\begin{array}{l}\text { Prosthodontic } \\
\text { complications }\end{array}$ & Peri-implant mucositis, peri- \\
\hline $\begin{array}{l}\text { Biological } \\
\text { complications }\end{array}$ & $\begin{array}{l}\text { implantitis, bone loss, implant } \\
\text { loss, soft tissue hyperplasia, } \\
\text { fistulae }\end{array}$ \\
Mechanical & $\begin{array}{l}\text { Screw loosening and fracture, } \\
\text { chipping or fracture of the } \\
\text { restoration, fixture fracture, loss } \\
\text { of retention, decementation, } \\
\text { abutment fracture } \\
\text { Missing interdental papillae, } \\
\text { complications } \\
\text { mucosal recession, poor } \\
\text { restoration contour and shade } \\
\text { mismatch }\end{array}$ \\
\hline
\end{tabular}

\section{BIOLOGICAL COMPLICATIONS}

Peri- implant diseases- Peri-implant mucositis and peri-implantitis together constitute the periimplant diseases, which can be defined as inflammatory reactions around the dental implants. $^{8}$ Patients with the history of the periodontal disease have higher chances of periimplant diseases.

Peri-implant mucositis is the inflammatory condition of the soft tissues around the dental implants. It is a reversible process and it does not affect the level of the marginal bone. According to several studies, the prevalence of peri-implant mucositis is around $48-50 \%$. Some of the common features of peri-implant mucositis includeinflammed soft tissue, bleeding on probing, 4-5 $\mathrm{mm}$ of probing depth, gingival cuffing, and pus formation. Peri-implant mucositis can be treated conservatively. Routine dental checkup, maintenance of oral hygiene along with antiseptic mouthwash should be used. ${ }^{9,10}$

Peri-implantitis affects the soft tissues around the dental implants along with bone loss which is irreversible in nature. ${ }^{11}$ Bone loss in case of periimplantitis is beyond the physiological limits of the bone remodeling. Pain, mobility, bleeding on probing, increasing probing depths over a period of time, exudation, recession and exposed threads of the implant are the clinical findings in the case of peri-implantitis. ${ }^{12}$ Exudation around the dental implant for $>2$ weeks requires immediate intervention. Although, deep probing depth is usually associated with the bone loss, many dental implants with pocket depths of $4-6 \mathrm{~mm}$ have been reported which were rigid and stable without any future loss of bone. ${ }^{13}$

High frequency of peri-implantitis has been reported in the patients who smoked regularly compared to the patients who did not have the habit of smoking. Other risk factors include female gender, age $>60$ years, poor oral hygiene, bruxism, diabetes, osteoporosis, hyperparathyroidism, history of radiation therapy and genetics. ${ }^{14}$

Management of peri-implantitis should be started as early as it is diagnosed. Treatment can be instituted by local and systemic methods. Surgery is required in few cases. Local treatment methods include mechanical debridement, subgingival irrigation using the antiseptic solution such as chlorhexidine and local drug delivery. In untreated severe cases, local treatment should be accompanied with systemic antibiotics. Surgical treatment includes opening the flap for the debridement and decontamination of dental implants using various pharmaceutical agents. Lasers are also used for this purpose. ${ }^{13}$

Bone loss - The level of the crestal bone is a significant marker for implant health and stability. Bone loss may occur secondary to the excessive occlusal loading or bacteria. After the dental implant surgery, some amount of bone loss occurs during the phase of tissue healing and osseointegration. If an excess amount of load is applied at the bone- implant interface, the stress induced bone loss is initiated. Due to continued overloading of the implant and bone loss, crevicular sulcus becomes deeper and is populated by anaerobic bacteria, leading to excessive periodontal destruction. To avoid bone loss, occlusal loading should be within the physiological limits of the bone and adverse occlusal forces should be minimized. ${ }^{15}$

Soft tissue hyperplasia- Incidence rate of $15-20 \%$ has been reported in a 9 year follow-up study. Hyperplastic growth of the soft tissues may occur due to poor oral hygiene and plaque accumulation around the dental implants. Other causes include reduced width of the attached gingival, poor fit of the framework, and dead space beneath the framework. ${ }^{16}$ Treatment of soft tissue hyperplasia includes removal of the underlying cause and oral prophylaxis. In few cases, surgical correction may be required. Electrosurgery should be avoided. Patient should be encouraged to maintain the good oral hygiene and regular follow up. 
Fistulae: Only 1-2\% cases of the fistulae have been reported at the interface between the dental implant and abutment. ${ }^{1}$ Fistulae are more common in cement-retained implant restorations. Predisposing factors for fistulae include loosening of abutment screw, poor fit of the framework and prosthesis. Fistulae should be treated with $0.2 \%$ chlorhexidine gluconate solution. An adequate amount of torque should be applied while placing the prosthesis. In case of ill-fitting prosthesis, restoration with a new prosthesis should be considered. $^{17}$

\section{MECHANICAL COMPLICATIONS:}

Natural dentition is cushioned with the periodontal ligament to adapt against occlusal forces. When occlusal forces exceed the adaptive capacity of the oral tissues, it may result in trauma from occlusion. Excessive functional and parafunctional forces produce adverse effects on the structural integrity of the dental implant and its components. As the periodontal ligament is absent in dental implant, adverse occlusal forces may cause mechanical failure of the implant restoration. $^{18}$

Screw loosening and fracture- According to several systematic reviews, screw loosening is the most common mechanical complication which is associated with the single implant-supported restoration. The factors which cause loosening of screw include:-

- Application of inadequate amount of torque

- Poor fit of the restoration/prosthesis

- Lack of antirotation characteristics /screw design associated with implant components

- Excessive loading of the implant ${ }^{19}$

It has been reported that the incidence of screw loosening is most commonly associated with the external-hex type of the implant system. Decreasing incidence of screw loosening was noticed in the case of single implant restorations if an adequate amount of initial torque and anti rotation features are used. Screw loosening can be minimized by using torque twice at 5-6-minute interval, shallow cuspal inclinations, reducing the amount of adverse occlusal forces. Internal connection implant system should be preferred over the external hex connection type of implant system.

Fracture of the implant abutment and prosthesis screw may occur as a consequence of repeated screw loosening due to the metal fatigue. Improper implant components, reusing the loosened screw, excessive load, ill-fitting prosthesis are the prime causes for the screw fracture. $^{20}$

Fracture of the screw components can be better managed by its prevention. Proper treatment planning for the positioning and number of implants should be done. The number of the dental implants should be decided with caution so that occlusal loading is minimized. The prosthesis should be checked for fit and design. The prosthesis should align along the axial forces and oblique forces should be avoided. The patient should be advised to follow post-operative instructions and periodic checkup.

If the screw gets fractured it should be retrieved. A fractured abutment screw can be retrieved using hemostat, self-made screw driver, special retrieval kit provided by specific implant systems. Hemostat can be used if the fractured segment is seen above the surface of the implant. $^{21}$

Chipping/fracture of the restoration: Chipping and fracture of the restoration is most commonly observed in partial fixed implant-supported prostheses with external connection implants, whereas it is the second most common mechanical complication reported in metal and metal- ceramic single implant restorations. ${ }^{22}$

If a small fracture is present in the posterior non-esthetic zone, it should be smoothened whereas larger defects are repaired. Several systems for the intra-oral repair of the metal ceramic restoration have been introduced (eg; Cojet), which can be used for such complications. Laboratory repair should be preferred compared to the intra-oral repair because the clinical performance of these repairs is uncertain. ${ }^{23}$

Chipping/ fracture of the restoration can be minimized by:

- Reducing size of the occlusal table

- Providing uniform thickness and support for veneering ceramic

- $\quad$ Shallow cusp height

- Avoiding excessive occlusal contacts ${ }^{24}$

Loss of retention and Decementation- Loss of retention can be seen in the case of poor retention and resistance form of the implant abutment. Selection of the implant abutment should be done with caution to prevent this complication. In case of inadequate space available for the restoration, implant should be placed at increased depth within the anatomical and physiological limits of the bone. Decementation of the implant supported restoration can be prevented by using glass 
ionomer and resin cements. According to several studies, incidence rate of decementation has been reported around 5-6\% with the follow-up period of 6 years. $^{25}$

Fixture fracture- Fracture of the implant fixture is a rare complication. Adell found that only 3-6\% cases in maxilla and $3 \%$ cases in mandible were associated with fracture of the implant fixture. ${ }^{26}$ The implant fixture fracture may occur due to following reasons:-

- Defective material and design of the implant

- Absence of passive fit of the restoration

- Occlusal overload

- Narrow diameter

- Parafunctional habits

- Long cantilever design

Rangert et al proposed that large diameter implant should be used in molar and premolar region to reduce the chances of fixture fracture.

Treatment of fractured implant fixture includes its removal with the help of trephine bur and placement of larger diameter implant. After successful osseointegration of the replaced implant prosthesis should be given. To reduce the incidence of the fixture fracture occlusal overload, cuspal inclination and size of the prosthetic crown should be corrected. ${ }^{27}$ Reduction of the cantilever length was suggested by Shackleton and Slabbert. They proposed that short cantilever reduces the excessive load on the implant. ${ }^{28}$ The maximum length of the cantilever for mandible is $15-20 \mathrm{~mm}$ and for maxilla is $10 \mathrm{~mm}$. It is suggested that careful, periodic occlusal evaluation and analysis before and after implant restorations should be carried out. A sound adoption of biomechanical principles must also be considered in the planning of combined tooth and implant supported partial dentures. $^{29}$

Abutment fracture- Abutment fracture is a rare complication associated with the dental implants. In a 5 year study, only $0.5 \%$ cases were reported with the implant abutment fracture. To prevent implant abutment fracture following factors should be considered:

- Abutment should have adequate mechanical strength to resist occlusal forces and metal fatigue

- It should have a well fitting surface with the other components

- In case of cement-retained implant restoration, adequate retention and resistance form should be present
Till now, titanium has proven to be the most successful abutment material except few mechanical complications. ${ }^{30}$

\section{ESTHETIC COMPLICATIONS}

Esthetic results of the dental implants cannot be predicted. $10 \%$ incidence rate of esthetic implant complication has been reported by Henry et al in a 5-year study. Several restorative and anatomical factors can cause esthetic complications in dental implant treatment. Some of the common esthetic complications reported include:-

- Poor restoration contour and shade mismatch

- Missing interdental papillae, mucosal recession

- Malposed implant

Higginbottom and colleagues said that the dental implant restoration should resemble the natural tooth completely. The goal of the dental implant treatment should be the replacement of the missing teeth with a natural looking restoration which blends with the surrounding tissues. $^{31}$

Replacement of single missing maxillary teeth in the patients with high esthetic demand is a difficult task. In case of high smile line, excessive exposure of the adjacent soft tissues and the other deficiencies make the restoration even more challenging. Esthetic implant complication can be minimized by the proper treatment plan. The final restoration should be used as a guide for 3dimensional positioning of the dental implant which can be regarded as key for esthetics. The outcome of the treatment is more appreciated by the patient compared to the dentist hence the patients should be informed about the limitations of the esthetic results. ${ }^{32}$

Surgical guides should be used for location and angulation of the dental implants. In case of poor angulation of the implant, angled abutment may be used to solve the esthetic issues. At least 1.5 $\mathrm{mm}$ of space should be present between the natural tooth and the dental implant. Two dental implants should be placed with 3 to $4 \mathrm{~mm}$ of space in between. This will reduce the resorption of the crestal bone and will help in preserving the soft tissues. ${ }^{33}$ A distance of 5-6 mm or lesser should be maintained between the base of the proximal contact and the crest of the alveolar bone for the intact papilla. To prevent the gingival recession in case of thin facial bone, placing the implant $3 \mathrm{~mm}$ palatal to the facial bone has been suggested. Other methods include guided bone regeneration, 
onlay grafts, block bone graft along with barrier membrane and distraction osteogenesis. ${ }^{34}$

The thin gingival biotype is more susceptible for the gingival recession hence connective tissue grafting may be required. Sometimes color change around the dental implants has been noticed when the gingival thickness is $<2 \mathrm{~mm}$. Zirconia abutment along with all ceramic restoration should be used to prevent such complication. Application of pink colored porcelain on the abutment neck has also been advocated to prevent discoloration the surrounding gingival tissues.

Immediate implant, socket augmentation and provisionalization of the dental implants should be considered for the esthetic outcome of the treatment. $^{35}$

\section{CONCLUSION}

The success of the dental implants has its own limitations. The dentist should have a thorough knowledge regarding all the complications associated with the dental implants, prevention strategies, and their management. Follow up after every 6 months has been advocated for the dental implant restorations. The patient should be informed about the anticipated complications and the probable outcome of the treatment.

\section{REFERENCES}

1. Vere J, Bhakta S, Patel R. Prosthodontic complications associated with implant retained crowns and bridgework: a review of the literature. $\mathrm{Br}$ Dent J. 2012 Mar 23;212(6):267-72. Available from: http://dx.doi.org/10.1038/sj.bdj.2012.225.

2. Fuentealba $\mathrm{R}$, Jofré J. Esthetic Failure in Implant Dentistry. Dental Clinics of North America. 2015 Jan;59(1):227-46. Available from:

http://dx.doi.org/10.1016/j.cden.2014.08.006

3. Al-Sabbagh M, Bhavsar I. Key Local and Surgical Factors Related to Implant Failure. Dental Clinics of North America. 2015 Jan;59(1):1-23. Available from: http://dx.doi.org/10.1016/j.cden.2014.09.001

4. Jung RE, Pjetursson BE, Glauser R, Zembic A, Zwahlen M, Lang NP. A systematic review of the 5-year survival and complication rates of implant-supported single crowns. Clinical Oral Implants Research. 2008 Feb;19(2):119-30. Available

from: http://dx.doi.org/10.1111/j.1600-

0501.2007.01453.x.

5. Thalji G, Bryington M, De Kok IJ, Cooper LF. Prosthodontic Management of Implant Therapy. Dental Clinics of North America. 2014 Jan;58(1):207-25. Available from: http://dx.doi.org/10.1016/j.cden.2013.09.007

6. Camargo IB, Van Sickels JE. Surgical Complications After Implant Placement. Dental Clinics of North America. 2015 Jan;59(1):57-72. Available from: http://dx.doi.org/10.1016/j.cden.2014.08.003

7. Misch K, Wang H-L. Implant Surgery Complications: Etiology and Treatment. Implant Dentistry. 2008 Jun;17(2):159-68. Available from: http://dx.doi.org/10.1097/id.0b013e3181752 f61.

8. Academy Report: Peri-Implant Mucositis and Peri-Implantitis: A Current Understanding of Their Diagnoses and Clinical Implications*. Journal of Periodontology. 2013 Apr;84(4):436-43. Available from: http://dx.doi.org/10.1902/jop.2013.134001.

9. Alani A, Bishop K. Peri-implantitis. Part 2: Prevention and maintenance of peri-implant health. Br Dent J [Internet]. Nature Publishing Group; 2014 Sep 26;217(6):289-97. Available from:

http://dx.doi.org/10.1038/sj.bdj.2014.809.

10. Renvert S, Persson GR. Periodontitis as a potential risk factor for peri-implantitis. Journal of Clinical Periodontology. 2009 Jul;36:9-14. Available from: http://dx.doi.org/10.1111/j.1600051x.2009.01416.x.

11. Sanz M, Chapple IL. Clinical research on periimplant diseases: consensus report of Working Group 4. J Clin Periodontol. 2012 Feb;39:202-6. Available from: http://dx.doi.org/10.1111/j.1600051x.2011.01837.x.

12. Alani A, Kelleher M, Bishop K. Peri-implantitis. Part 1: Scope of the problem. Br Dent J. 2014 Sep 26;217(6):281-7. Available from: http://dx.doi.org/10.1038/sj.bdj.2014.808.

13. Lekholm U, Adell R, Lindhe J, Brånemark P-I, Eriksson $B$, Rockler $B$, et al. Marginal tissue reactions at osseointegrated titanium fixtures. International Journal of Oral and 
Maxillofacial Surgery. 1986 Feb;15(1):53-61. Available from: http://dx.doi.org/10.1016/s03009785(86)80011-4.

14. Dawson DR, Jasper S. Key Systemic and Environmental Risk Factors for Implant Failure. Dental Clinics of North America. 2015 Jan;59(1):25-39. Available from: http://dx.doi.org/10.1016/j.cden.2014.09.002

15. Oh T-J, Yoon J, Misch CE, Wang H-L. The Causes of Early Implant Bone Loss: Myth or Science? Journal of Periodontology. 2002 Mar;73(3):322-33. Available from: http://dx.doi.org/10.1902/jop.2002.73.3.322.

16. Goodacre CJ, Kan JYK, Rungcharassaeng K. Clinical complications of osseointegrated implants. The Journal of Prosthetic Dentistry. 1999 May;81(5):537-52. Available from: http://dx.doi.org/10.1016/s00223913(99)70208-8.

17. Wittneben J-G, Millen C, Brägger U. Clinical Performance of Screw- Versus CementRetained Fixed Implant-Supported Reconstructions-A Systematic Review. Int J Oral Maxillofac Implants. 2014 Jan;29(Supplement):84-98. Available from: http://dx.doi.org/10.11607/jomi.2014suppl.g 2.1 .

18. Schwarz MS. Mechanical complications of dental implants. Clinical Oral Implants Research. 2000 Sep;11:156-8. Available from: http://dx.doi.org/10.1034/j.16000501.2000.011s1156.x.

19. Cavazos E, Bell FA. Preventing loosening of implant abutment screws. The Journal of Prosthetic Dentistry. 1996 May;75(5):566-9. Available from: http://dx.doi.org/10.1016/s00223913(96)90464-3.

20. Yilmaz B, McGlumphy E. A technique to retrieve fractured implant screws. The Journal of Prosthetic Dentistry. 2011 Feb;105(2):1378. Available from: http://dx.doi.org/10.1016/s00223913(11)60015-2.

21. Bhandari S, Aggarwal N, Bakshi S. Ultrasonic Oscillations for Conservative Retrieval of a Rare Fracture of Implant Healing Abutment. Journal of Oral Implantology. 2013 Aug;39(4):475-8. Available from: http://dx.doi.org/10.1563/aaid-joi-d-1100126.
22. Örtorp A, Jemt T. Clinical Experiences of Implant-Supported Prostheses with LaserWelded Titanium Frameworks in the Partially Edentulous Jaw: A 5-Year Follow-up Study. Clinical Implant Dentistry and Related Research. 1999 Oct;1(2):84-91. Available from: http://dx.doi.org/10.1111/j.17088208.1999.tb00096.x..

23. Chee W, Jivraj S. Screw versus cemented implant supported restorations. $\mathrm{Br}$ Dent J. 2006 Oct 21;201(8):501-7. Available from: http://dx.doi.org/10.1038/sj.bdj.4814157.

24. Sadid-Zadeh R, Kutkut A, Kim H. Prosthetic Failure in Implant Dentistry. Dental Clinics of North America. 2015 Jan;59(1):195-214. Available from: http://dx.doi.org/10.1016/j.cden.2014.08.008

25. Bragger $U$, Karoussis I, Persson R, Pjetursson B, Salvi G, Lang NP. Technical and biological complications/failures with single crowns and fixed partial dentures on implants: a 10-year prospective cohort study. Clin Oral Implants Res. 2005 Jun;16(3):326-34. Available from: http://dx.doi.org/10.1111/j.16000501.2005.01105.x.

26. Tagger Green N, Machtei EE, Horwitz J, Peled M. Fracture of Dental Implants: Literature Review and Report of a Case. Implant Dentistry. 2002 Jun;11(2):137-43. Available from: http://dx.doi.org/10.1097/00008505200204000-00014.

27. AL Quran FAM, Rashan BA, AL-Dwairi ZN. Management of Dental Implant Fractures. A Case History. Journal of Oral Implantology. 2009 Aug;35(4):210-4. Available from: http://dx.doi.org/10.1563/1548-133635.4.210.

28. Shackleton JL, Carr L, Slabbert JCG, Becker PJ. Survival of fixed implant-supported prostheses related to cantilever lengths. The Journal of Prosthetic Dentistry. 1994 Jan;71(1):23-6. Available from: http://dx.doi.org/10.1016/00223913(94)90250-x.

29. Muroff FI. Removal and Replacement of a Fractured Dental Implant: Case Report. Implant Dentistry. 2003 Sep;12(3):206-10. Available from: http://dx.doi.org/10.1097/01.id.0000084168. 57434.f1.

30. Pjetursson BE, Brägger U, Lang NP, Zwahlen M. Comparison of survival and complication 
rates of tooth-supported fixed dental prostheses (FDPs) and implant-supported FDPs and single crowns (SCs). Clinical Oral Implants Research. 2007 Jun;18:97-113. Available from:

http://dx.doi.org/10.1111/j.1600-

0501.2007.01439.x.

31. Misch K, Wang H-L. Implant Surgery Complications: Etiology and Treatment. Implant Dentistry. 2008 Jun;17(2):159-68. Available from: http://dx.doi.org/10.1097/id.0b013e3181752 f61.

32. Almog DM, Torrado E, Meitner SW. Fabrication of imaging and surgical guides for dental implants. The Journal of Prosthetic Dentistry. 2001 May;85(5):504-8. Available from:

http://dx.doi.org/10.1067/mpr.2001.115388.

33. Tarnow DP, Cho SC, Wallace SS. The Effect of Inter-Implant Distance on the Height of Inter-
Implant Bone Crest. Journal of Periodontology. 2000 Apr;71(4):546-9. Available from: http://dx.doi.org/10.1902/jop.2000.71.4.546.

34. Siqueira S, Pimentel SP, Alves RV, Sendyk W, Cury PR. Evaluation of the Effects of BuccalPalatal Bone Width on the Incidence and Height of the Interproximal Papilla Between Adjacent Implants in Esthetic Areas. Journal of Periodontology. 2013 Feb;84(2):170-5. Available from: http://dx.doi.org/10.1902/jop.2012.110638.

35. Ishikawa-Nagai S, Da Silva JD, Weber HP, Park SE. Optical phenomenon of peri-implant soft tissue. Part II. preferred implant neck color to improve soft tissue esthetics. Clin Oral Implants Res. 2007 Oct;18(5):575-80. Available from: http://dx.doi.org/10.1111/j.16000501.2007.01390.x. 